\title{
Recommendation System: Techniques, Evaluation and Limitations
}

\author{
Shruthi N, Sunitha R S, Lincy Mathews
}

\begin{abstract}
For the benefits of the user in selecting items based on their interests, the recommendation technology is developed in different domains. A recommender system is one of the major techniques, that handles information overload problem of Information Retrieval by suggesting users with appropriate and relevant items. This paper surveys recommendation technology, the challenges and its solutions. Recommendation technology is applied in many areas like movies, videos, books, research papers, libraries, music, news, tourism, etc. This survey is useful for the further implementation and analysis of how users are adapting these technologies and how helpful it is for the user. This work also helps understand the different techniques of recommendation systems and how they can be evaluated.

Keywords: collaborative filtering, content-based filtering, context-based filtering, hybrid approach, recommendation system.
\end{abstract}

\section{INTRODUCTION}

$\mathrm{P}_{1}$

Preference driven recommendation software to consumers based on their interest are called as Recommender Systems (RSs). The method by which the systems ascertain the preferences are implicit or explicit. The implicit method relies on browsing and purchasing histories of the consumers, geographical locations, etc. for the collection of data. The explicit method uses survey-based data collection mechanism, such as providing ratings, filling forms. Diverse set of application domains which include but not limited to are e-commerce, online streaming entertainment services, tours and travel services.

In reality, the objects of interest, or preference are habitually browsed in the beginning. For example, the mother of a baby might be expected to look for baby products, a young person might be expected to search for games, electronics, course materials, etc. Recommendation Systems, as per their design, is a solution which aids with recommending different objects based on their preference. The suitability of the system has been observed in diverse fields including e-commerce such as Amazon, Flipkart, etc. Additionally, it also has evidently proven its potential in travel sites such as Trip Advisor, MakeMyTrip, etc [1].

Revised Manuscript Received on October 30, 2019.

* Correspondence Author

Shruthi $\mathbf{N}^{*}$, pursuing M. Tech in IS\&E department of RIT

Sunitha R., assistant professor in IS\&E department of RIT.

Lincy Mathews, assistant professor in IS\&E department of RIT.

(C) The Authors. Published by Blue Eyes Intelligence Engineering and Sciences Publication (BEIESP). This is an open access article under the CC BY-NC-ND license (http://creativecommons.org/licenses/by-nc-nd/4.0/)
This paper categorizes different recommendation system in Section 2. Section 3 gives a detailed view of various types of recommendation system. Section 4 explains how the recommendation system can be evaluated. Section 5 briefly explains the different obstacles faced by a recommendation system.

\section{CATEGORIES OF RECOMMENDATION SYSTEM}

The consumer profile is collected online through form filling, object feature and the description information of the interested products by the consumer. Nonetheless, the biggest obstacle that is faced is combining the consumer data and the object. To overcome these obstacles, recommendation system utilizes methods such as Collaborative Filtering (CF), Content-based Filtering (CBF), Hybrid Approach. The description of each of the aforementioned methods are as follows [2]

Collaborative filtering:

The recommendations provided by this system are based on the preferences of the community. The recommendations for an Object are based on the reviews provided by other consumers [3], irrespective of any demographic parameters. Content based filtering (CBF):

Content-based system endeavours to provide recommendations based on the reviews of target consumer and the characteristics corresponding to the specific object [7]. This recommendation system is suitable only when that specific objected has been reviewed previously, that is, they possess a review history

Hybrid approach:

The formerly mentioned methods have their own constrains and disadvantages. To overcome these disadvantages, investigators initiated a new type of recommendation system, called as hybrid recommendation system. This method provides recommendations based on weighted average of collaborative and content-based recommendation [2].

Context Based Recommendation System:

In numerous applications like recommending a holiday package individualizes website content or a movie, it is not always adequate to only give thought to users and itemscontextual information for a recommendation system is also imperative under certain situation. For instance, a clothes recommender system furnishes different items based on seasons [20]. 


\section{DEFINITIONS, EXPLAINATIONS AND LIMITATIONS}

\section{A. Collaborative Filtering}

Collaborative filtering is an approach to foretell concealed proclivities of the users by making use of the proclivities from the other users. It reckons the sameness based on user and item. The snags faced by Collaborative filtering are scalability, cold start and data sparsity.

It introduces three main techniques: Memory-based CF, Model-based CF, Hybrid recommendation. Described in Table I.

Table- I: Collaborative filtering techniques.

\begin{tabular}{|c|c|c|c|}
\hline $\begin{array}{l}\text { CF } \\
\text { techniques }\end{array}$ & Annotation & Pros & Cons \\
\hline $\begin{array}{l}\text { Memory-bas } \\
\text { ed CF }\end{array}$ & $\begin{array}{l}\text { Catch } \\
\text { resembling } \\
\text { users, using } \\
\text { cosine or } \\
\text { Pearson } \\
\text { correlation } \\
\text { and consider } \\
\text { the weighted } \\
\text { average of } \\
\text { ratings. }\end{array}$ & $\begin{array}{l}\text { *Creation is } \\
\text { not } \\
\text { burdensome } \\
\text { * There is no } \\
\text { need to } \\
\text { scrutinize the } \\
\text { recommended } \\
\text { items' } \\
\text { content.[14] }\end{array}$ & $\begin{array}{l}\text { * Performance } \\
\text { scale down } \\
\text { when the data } \\
\text { is sparse. } \\
\text { * Counts on } \\
\text { user ratings. } \\
\text { * New users or } \\
\text { items can't be } \\
\text { recommended } \\
\text { [2]. }\end{array}$ \\
\hline $\begin{array}{l}\text { Model-based } \\
\text { CF }\end{array}$ & $\begin{array}{l}\text { Uses machine } \\
\text { learning to } \\
\text { catch users' } \\
\text { ratings on } \\
\text { items that are } \\
\text { not rated. }\end{array}$ & $\begin{array}{l}\text { * Boosts the } \\
\text { performance } \\
\text { of the } \\
\text { prediction. } \\
\text { * addresses } \\
\text { the } \\
\text { scalability, } \\
\text { sparsity and } \\
\text { other issues in } \\
\text { an improved } \\
\text { way.[2] }\end{array}$ & $\begin{array}{l}\text { * Building this } \\
\text { model is a } \\
\text { big-ticket. } \\
\text { * lose fruitful } \\
\text { information on } \\
\text { techniques of } \\
\text { dimensionality } \\
\text { reduction [17] }\end{array}$ \\
\hline $\begin{array}{l}\text { Hybrid } \\
\text { recommenda } \\
\text { tion }\end{array}$ & $\begin{array}{l}\text { Conjoins the } \\
\text { CF with other } \\
\text { recommendat } \\
\text { ion } \\
\text { techniques to } \\
\text { produce } \\
\text { recommendat } \\
\text { ion or } \\
\text { prediction. }\end{array}$ & $\begin{array}{l}\text { * Boosts the } \\
\text { performance } \\
\text { of the } \\
\text { prediction. } \\
\text { * overcome } \\
\text { the } \\
\text { constraints of } \\
\text { CF and } \\
\text { content-based } \\
\text { filtering. } \\
\text { * addresses } \\
\text { the gray } \\
\text { sheep, } \\
\text { sparsity and } \\
\text { other issues. } \\
\text { [3,7] }\end{array}$ & $\begin{array}{l}\text { * Tortuous for } \\
\text { implementatio } \\
\mathrm{n} \\
\text { *Expense for } \\
\text { implementing } \\
\text { is high. } \\
\text { * Urges } \\
\text { external } \\
\text { information } \\
\text { which are } \\
\text { usually not } \\
\text { available.[3] }\end{array}$ \\
\hline
\end{tabular}

\section{B. Content Based Recommendation system}

Keeping the meta data under consideration content-based filtering recommends items to the user [4]. This form of filter does not engage other users. Hinged on what the user prefers, the algorithms pick the items that are similar to it. For instance, if the user likes any particular movie, the movies that are of the same genre will be recommended [5][6]. Diversity of recommendation in this type is subjacent but works even if the users' ratings are available or not.

This method is incapable of achieving efficient results if the specific object lacks a review history. Furthermore, the method relies on the textual data provided by the target consumer. Recommendation systems usually tags every object with a particular keyword and an associated weight [7] When the target consumer inputs the specific product name, Recommendation system enlists the products corresponding to that product using the assigned keyword and weight.

Fig.1 exhibit the stream of information in a content-based recommender system [7]. Pertinent entities of an item and its relation forms input. Item Modelling gives the important features of item. The features are applied to recommender system. After which it gives the output of various recommended items.

Favored circumstances of Content based filtering are:

- Content based filtering totally depends on the users to build their own profile rather than depending on other users' ratings or interests.

- Capable of recommending the items that are not rated by any user.

- Working can be easily understood by explicitly describing why the item is displayed on the recommended list.[4]

Unfavored circumstances of Content based filtering are:

- The users' preferences must be clearly understood before the item is recommended [7].

- Recommendations can be made based on existing interests of the user.

- Recommended items are those similar to

- his/her interests, discovery of new items is not possible.

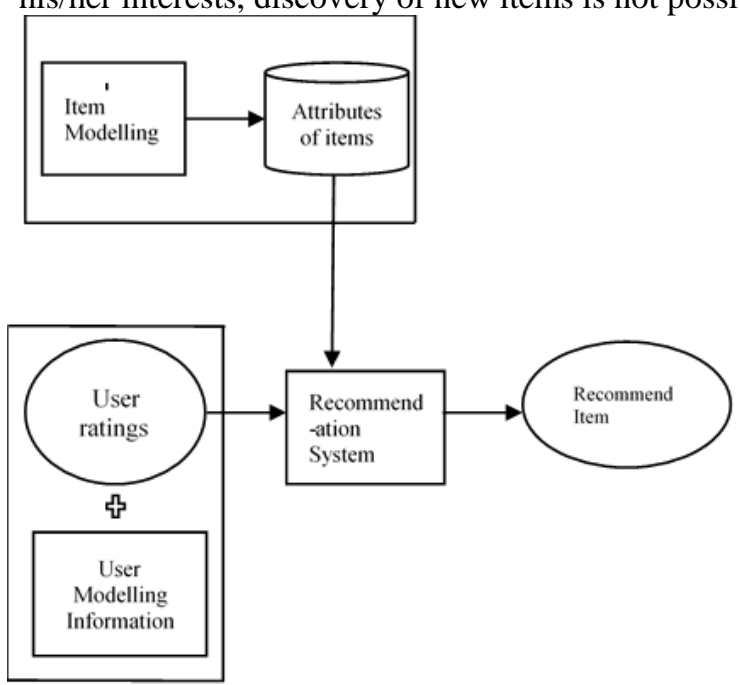

Fig. 1.Content based Recommendation system. 


\section{Hybrid Approach}

In order to run-over the limitations of the of collaborative and content-based filtering, hybrid approach integrate both. Hybrid approach can be combined in divergent manners [39]: 1) Separately implementing collaborative and content-based filtering and combining both predictions. 2) Using collaborative properties in content based or vice versa. 3) Sculpting collaborative and content based at once.

Classification of Hybrid recommender systems can be done in different ways:

- Weighted: Diverse recommendation segments scores are linked together statistically. Making use of the additive formula the score is aggregated from each factor. [39]

- Switching: Hybrid approach is applied by choosing one particular component out of the recommended components. [39]

- Mixed: Different ways of the recommendation will be provided by different Recommenders, which will be displayed together to the user. Considering on how the class is being rated, they will be presented on merging of multiple rated list into single rated list. [39]

- Featured Combination: Two categories of Recommendation components exist in this particular class, classified as contributing recommender and actual recommender. Throwing the feature of one source to the other component source is the feature of contribution recommender. Actual recommender works on the concept which depends on the data that is being modified by the contributing recommender. [39]

- Feature Augmentation: The combinations possess similar features to this particular class but the only difference is the contributing provides novel characteristics. It is more flexible compared to feature combination method. [39]

- Cascade: If there is a conflict on what item has to be recommended, priorities are assigned to the items. The one with highest priority will be recommended. [39]

- Meta-level: Either one of the contributing or actual recommender that completely substitutes data first will be considered and recommended. [39]

\section{Context based Recommendation system}

The conventional Recommender methods recommends the top $n$ items with higher prediction that merges the data about users, items, implicit or explicit ratings and predict the ratings for the items, which are usually not visible to the user. The users' interests may vary based on the context and also depends on the time of user interaction with the system. To define an event or a situation, context will be used. The information that can be characterized for an event or a situation can be referred as context. It can be about the user, the item or the activity of interaction. For example, a person looking to go on a vacation can get recommendations from a tourist website. The user will be recommended to visit a beach during summer, hill station during winter and so on. Here season acts as a context and the recommendation will be done accordingly.

Contextual based recommendation can be classified as:

1) Pre-filtering 2) Post-filtering 3) Contextual filtering described in Table II.

The ability to allow the deployment of numerous 2D-RS techniques as data filtering techniques can be considered as the advantages of pre-filtering and post-filtering approaches.
The pre-filtering uses the exact context and post-filtering adjusts the recommendation and the contextual modeling approach incorporates the contextual information.

Table- II: Classification of Context-based recommendation

\begin{tabular}{|c|l|l|}
\hline $\begin{array}{c}\text { Context based } \\
\text { recommendatio } \\
\text { n Methods }\end{array}$ & \multicolumn{1}{|c|}{ Explanation } & References \\
\hline & $\begin{array}{l}\text { Before computing the } \\
\text { final contextual } \\
\text { recommendation, all the } \\
\text { garbage scores are refined } \\
\text { out. }\end{array}$ & $\begin{array}{l}{[8,9,17,23,3} \\
7,38]\end{array}$ \\
\hline Pre-filtering & $\begin{array}{l}\text { After computing the final } \\
\text { contextual } \\
\text { recommendations, the } \\
\text { garbage scores are }\end{array}$ & {$[8,9,19,27,3$} \\
& refined. & \\
\hline & $\begin{array}{l}\text { In the recommendation } \\
\text { generating algorithm, the } \\
\text { context that are identified }\end{array}$ & $\begin{array}{l}{[19,20,25,2} \\
9,33,27]\end{array}$ \\
\hline Contextual & are used. & \\
\hline
\end{tabular}

The limitations faced by the recommendation methods are listed down in Table III.

Table- III: Limitations of recommendation methods

\begin{tabular}{|c|c|}
\hline $\begin{array}{c}\text { Recommendation } \\
\text { methods }\end{array}$ & Limitations \\
\hline $\begin{array}{l}\text { Collaborative } \\
\text { Filtering }\end{array}$ & $\begin{array}{l}\text { - Requires large dataset of user and items for } \\
\text { a start. } \\
\text { - Standardized products must be used. } \\
\text { - Suffers from cold start. }\end{array}$ \\
\hline $\begin{array}{l}\text { Content based } \\
\text { Filtering }\end{array}$ & $\begin{array}{l}\text { - Accuracy is less compared to collaborative } \\
\text { filtering. } \\
\text { - Leads to overspecialization. }\end{array}$ \\
\hline Hybrid Approach & $\begin{array}{l}\text { - To get the right balance for combining the } \\
\text { methods a lot of work is required. }\end{array}$ \\
\hline $\begin{array}{l}\text { Context based } \\
\text { Filtering }\end{array}$ & $\begin{array}{l}\text { - Examining the validating the context. } \\
\text { - } \text { Method to extract the user preferences } \\
\text { based on context is a huge process. }\end{array}$ \\
\hline
\end{tabular}

\section{EVALUATION OF RECOMMENDATION SYSTEM}

The performance of the recommendation system can be gauged in three different ways [40]:

- Offline: It is the easiest and convenient method for evaluation that do not expect any user interaction. Based on the ground truth, the accuracy is measured.

- Online: One of the best methods for evaluating the recommender system. Using the click through rates (CTR), it gauges the recommendation acceptance in the real world.

- User study: The results of the user studies often depends on the question asked, even though it is considered as the optimal solution by the researchers. User study is carried out by considering the 
overall satisfaction of the system through ratings.

Evaluation metrics of recommendation system is described in Table IV.

Table- IV: Evaluation metrics

\begin{tabular}{|c|c|c|c|}
\hline $\begin{array}{l}\text { Gauging } \\
\text { Criteria }\end{array}$ & Case & Criteria & Reference \\
\hline Precision & $\begin{array}{l}\text { Considering the } \\
\text { relevant retrieved } \\
\text { documents, the } \\
\text { proportion is } \\
\text { measured. }\end{array}$ & $\begin{array}{l}\text { From the retrieved } \\
\text { set, the } \\
\text { non-relevant } \\
\text { document will be } \\
\text { rejected }\end{array}$ & $\begin{array}{l}{[9,10,11,12,} \\
13]\end{array}$ \\
\hline Precision & $\begin{array}{l}\text { Considering the } \\
\text { relevant retrieved } \\
\text { documents, the } \\
\text { proportion is } \\
\text { measured. }\end{array}$ & $\begin{array}{l}\text { From the retrieved } \\
\text { set, the } \\
\text { non-relevant } \\
\text { document will be } \\
\text { rejected }\end{array}$ & $\begin{array}{l}{[9,10,11,12,} \\
13]\end{array}$ \\
\hline Recall & $\begin{array}{l}\text { Considering the } \\
\text { retrieved documents } \\
\text { that are relevant, the } \\
\text { proportion is } \\
\text { measured. }\end{array}$ & $\begin{array}{l}\text { The system's } \\
\text { ability to fine the } \\
\text { relevant document } \\
\text { is measured. }\end{array}$ & $\begin{array}{l}{[8,9,10,15,1} \\
6]\end{array}$ \\
\hline f-measure & $\begin{array}{l}\text { The harmonic mean of } \\
\text { recall and precision is } \\
\text { measured. }\end{array}$ & $\begin{array}{l}\text { The balance } \\
\text { between precision } \\
\text { and recall is } \\
\text { gauged. }\end{array}$ & $\begin{array}{l}{[10,13,18,2} \\
5]\end{array}$ \\
\hline $\begin{array}{l}\text { Mean } \\
\text { absolute } \\
\text { error } \\
\text { (MAE) }\end{array}$ & $\begin{array}{l}\text { The accuracy of the } \\
\text { rating prediction is } \\
\text { measured }\end{array}$ & $\begin{array}{l}\text { Based on the user } \\
\text { specified ratings, } \\
\text { the deviation of the } \\
\text { recommendation is } \\
\text { measured. }\end{array}$ & $\begin{array}{l}{[23,24,26,2} \\
7,29]\end{array}$ \\
\hline $\begin{array}{l}\text { Root mean } \\
\text { square error } \\
\text { (RMSE) }\end{array}$ & $\begin{array}{l}\text { The accuracy of the } \\
\text { rating prediction is } \\
\text { measured }\end{array}$ & $\begin{array}{l}\text { It gives the } \\
\text { difference between } \\
\text { the actual value } \\
\text { and related data. }\end{array}$ & $\begin{array}{l}{[23,24,26,2} \\
8,31,35]\end{array}$ \\
\hline $\begin{array}{l}\text { Discounted } \\
\text { cumulative } \\
\text { gain (DCG) }\end{array}$ & $\begin{array}{l}\text { The top-n } \\
\text { recommendation } \\
\text { quality is measured }\end{array}$ & $\begin{array}{l}\text { It highlights the } \\
\text { precision at the top } \\
\text { of the rank and } \\
\text { neglects the recall. }\end{array}$ & $\begin{array}{l}{[21,23,26,3} \\
1,36]\end{array}$ \\
\hline
\end{tabular}

Table- IV: Continuation of Evaluation metrics.

\begin{tabular}{|l|l|l|l|}
\hline $\begin{array}{l}\text { Gaugin } \\
\text { g } \\
\text { Criteri } \\
\text { a }\end{array}$ & Case & Criteria & Reference \\
\hline $\begin{array}{l}\text { Mean } \\
\text { recipro } \\
\text { cal } \\
\text { rank } \\
\text { (MRR) }\end{array}$ & $\begin{array}{l}\text { When the } \\
\text { system } \\
\text { recommends } \\
\text { the first } \\
\text { relevant } \\
\text { precision, } \\
\text { based on the } \\
\text { ranking level } \\
\text { the result is } \\
\text { measured. }\end{array}$ & $\begin{array}{l}\text { The first } \\
\text { relevant } \\
\text { recommendatio } \\
\mathrm{n} \text { is focused. }\end{array}$ & {$\left[\begin{array}{l} \\
\text { (9,10,11,12,13,14 }\end{array}\right.$} \\
\hline $\begin{array}{l}\text { Click } \\
\text { through } \\
\text { rate }\end{array}$ & $\begin{array}{l}\text { Measures the } \\
\text { recommendati } \\
\text { ons that are } \\
\text { clicked. }\end{array}$ & $\begin{array}{l}\text { A broad view on } \\
\text { how the item } \\
\text { attracts the user } \\
\text { is provided. }\end{array}$ & {$[8,9,10,15,16,23$,} \\
\hline Purcha & The number of & The number of & {$[10,13,18,15,23,3$} \\
\hline
\end{tabular}

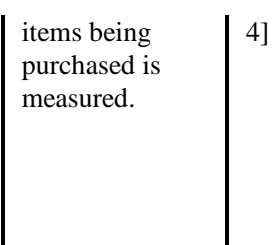

\section{STUMBLING BLOCKS OF RECOMMENDATION SYSTEM}

However, Recommendation system has displayed its suitability in diverse sectors, unfortunately it cannot overcome certain application obstacles which are as follows:

- Sparsity problem: As the name suggests, this issue occurs when consumers don't review the product while shopping online. This raises the issue of sparsity in the available reviews. Collaborative filtering method suffers from such issues as it uses the review matrix. [1][2][4]

- Cold start problem: This issue occurs when recommendation systems cannot generate review as the reviews for new products cannot be foreseen beforehand. This issue arises from two situations: on introduction of a new object into the recommendation system with no previous reviews for the object or the joining of a new user with no review record into the recommendation system. Hence, it tends to be critical for a recommendation system to generate options for a new user.

In the situation where there are similar objects consisting of dissimilar names are existing in the system then the recommendation system cannot establish the similarities between the objects. This scenario creates issues in the recommendation of objects and is called as synonymy. [1][2][4]

- Problem of scalability: This issue is observed when objects reviewed by users grows exponentially. This makes managing the large quantity of data by recommendation systems unsurmountable because of limited resources and extensive computational complication. [1][2][4]

- Gray sheep: This issue is observed when the options of a specific user do not match other users. [1][2][4]

- Shilling attacks: These attacks can be divided into two categories the nuke attack and push attack. Nuke attack refers to the scenario where a vendor tries to undermine the object reviews of their competitors. The push attack refers to the scenario where a vendor uses unmerited contraptions to propel the number of reviews of an object by that vendor compared to the objects manufactured by a different vendor. [1][2][4]

- Black sheep: This scenario is observed the options of a specific user relates to a tiny portion of the user pool. This renders the recommendation system incapable of generating preferences. [1][2][4]

\section{CONCLUSION}

The main attempt of the Recommendation system is to improve the accuracy of the personalized recommendations to the user based on their requirements. This paper also discusses the different techniques listed for recommendation process, different ways of evaluating and challenges faced by the recommender system.
Published By: Blue Eyes Intelligence Engineering \& Sciences Publication 


\section{REFERENCES}

1. BShapira, Ricci, L Rokach, and Francesco "Introduction to recommender systems" in Recommender Systems handbook, pp. 1-35, Springer US, 2011.

2. J.Bobadilla, F.Ortega, A. Hernando, A. Gutierrez, "Recommender systems survey," Knowledge-Based Systems, vol. 46, pp. 109-132, 2013.

3. C Kaleli and, Bilge A "A multi-criteria item based collaborative filtering framework," in 11th International Joint Conference Software Engineering, pp. 18-22, IEEE, 2014.

4. G Semersro, Pasquale, M De Gemmis, and Lops. "Content based recommender systems," in Recommender Systems handbook, pp. 73-105, Springer US, 2011.

5. Barbara, Jochen, and, Cimpa Nessel. "The movie oracle content-based movie recommendations," International Conference on Web Intelligence and Intelligent Agent Technology (WI-IAT), vol.3, pp.361-364, 2011.

6. Jain S Kumar,Chhavi, and Rana. "Building a Book Recommender system using time-based content filtering," in WSEAS on Computers, vol. 11, no. 2, pp. 27-33, Feb 2012.

7. M. Zhang, Yiqun Liu and YongF Zhang, "Incorporating Phrase-level Sentiment Analysis on Textual Reviews for Personalized Recommendation", International Conference on Web Search and Data Mining, pp. 435 - 440, February 2015.

8. J Thalmann, D Y-Smith, GuoZhang N, "Leveraging prior ratings for recommender systems in e-commerce”. Commer. Res. Appl. 2014, 13, 440-455.

9. V.Ricci, F.Cecaroni, Codina L. "Distributional semantic pre-filtering in context-aware recommender systems". User-Adapt. Interact. 2016, $26,1-32$.

10. A.Gorgog, U.Tuzhilin, Panniello M. "Comparing context-aware recommender systems in terms of accuracy and diversity". User-Adapt. Interact. 2014, 24, 35-65.

11. Mobasher B, Hriri, N, R Burke. Context-aware music recommendation based on latent topic sequential patterns. In Proceedings of the ACM Conference on Recommender Systems, Dublin, Ireland,9-13 September 2012; pp. 131-138.

12. K.Chiu,Chan.W Y, Yu.T. "A web search-centric approach to recommender systems with URLs as minimal user contexts". J. system. Software. 2011, 84.

13. Du, W, Wang Q, Ma, J.” A context-aware researcher recommendation system for university-industry collaboration on R\&D projects”. Deci's. Support Syst. 2017, 106, 46-57.

14. Rawashdeh, M, al Osman H.Hossain, M.S Saddik, Alhamid, M.F A. Towards context-sensitive collaborative media recommender system. Multimed. Tools Appl. 2015, 74.

15. M.F.Rawashdeh, M.Dong, H.Hossain, M.A.el Saddik, Alhamid, "A. Exploring latent preferences for context-aware personalized recommendation systems". IEEE Syst. 2016, 46, 615-623.

16. P Snie, Nawrocki, B. Czyzewski, J. "Learning Agent for a Service-Oriented "Context-Aware Recommender System in Heterogeneous Environment”. Inf. 2016, 35, 1005-1026.

17. Hossain, M.Alhamid, M. Rawashdeh, Dong, Alelaiwi, el Saddik,: “A collaborative context-aware framework for multimedia recommendations in an ambient intelligence environment" Multimedia Syst. 2016, 22, 587-601.

18. M Zangerle, ESpecht, G Pichl. "Towards a context-aware music recommendation approach" 2015 IEEE International Conference on Data Mining Workshop, 14-17 November 2015; pp. 1360-1365.

19. T Hussein, Linder $\mathrm{T}$ Gaulke ,Ziegler, J. "Hybrid: A software framework for developing context-aware hybrid recommender systems". User Model. Interact. 2014, 24, 121-174.

20. H Karagoz, Bagcii P. "Context-aware location recommendation by using a random walk-based approach”.Inf. Syst. 2016, 47, 241-260.

21. B Burke ,ZhengY, "Context recommendation using multi-label classification". In 2014 IEEE International on Web Intelligence (WI) and Intelligent ,Warsaw, Poland, 11-14 August 2014; pp. 288-295.

22. G Zhao, K Ma Yuan, Z Yuan Q Cong Sun, A. "Who, Where, When, and What: A Nonparametric Bayesian Approach to Context-aware Recommendation and Search for Twitter Users". ACM (TOIS)2015, 33, 2.

23. H Karagoz, P Bagci. "Context-aware friend recommendation for location based social networks using random walk". In 25th International Conference Companion on World Wide Web, Canada, 2016; pp. 531-536.
24. X.Song, Ren Haihong, E.; Song, "Context-aware probabilistic matrix factorization modeling for point-of-interest recommendation". Neurocomputing 2017, 241, 38-55.

25. E Song, Zhen C Haihong,"Contextual Modeling Probabilistic Tensor Factorization for Recommender Systems". Neurocomputing 2016, 205, 141-151.

26. Chen T He, X Kan," Context-aware image tweet modelling and recommendation". In Multimedia Conference, Amsterdam, The Netherlands, 15-19 October 2016; pp. 1018-1027.

27. B Twardowski. "Modelling Contextual Information in Session-Aware Recommender Systems with Neural Networks". ACM Conference on Recommender Systems, USA, 15-19 September 2016; pp. 273-276.

28. Hidassi, B,"Context-aware Preference Modeling with Factorization". In Proceedings of the ACM Conference on Recommender Systems, Austria, 2015; pp. 371-374.

29. H Long, B Yang, S Smola, Zha H Zheng, “ Learning recommender using context of user choice". In 34th International ACM Conference, China, 24-28 July 2011; pp. 295-304.

30. X.Aberer Liu, K. SoCo," A social network aided context-aware recommender system". International Conference on World Wide Web, Rio de Janeiro, Brazil, 2013; pp. 781-802.

31. W YanYu, Cui L Huang F,R Wen, Z Lu, " A novel context-aware recommendation algorithm with two-level SVD in social networks", Future Gener. Computer. Syst. 2017.

32. J Yoon Kim, S Lee, S Kim, Resource: Tensor factorization with data reduction for context-aware recommendations. J. Supercomputer. 2017, 1-11.

33. Valencia G, Col Mendoz, , R Rodrígue Gonzá A Colomo-Palacios, Rlor-Hernández, "Towards a knowledge-based probabilistic and context-aware social recommender system". Sci. 2017.

34. X Baltrunas, Oliver, N. "Multiverse recommendation: N-dimensional tensor factorization for context-aware collaborative filtering". In Fourth ACM Conference on Recommender Systems Spain, 26-30 September 2010; pp. 79-86.

35. Schmidtke Han J, H Xie, X Woo." Ordering recommendations using a hierarchical context model with granularity". 2014, 13, 85-98.

36. B Danjuma Kakudi ,Haruna Bichi A,H.A Herawan,"An Overview on the State-Of-The-Art Comparison of the Three-Contextualization Paradigms". In Technology (ICIT 2017), Amman, Jordan, 17-18 May 2017.

37. Kim Lee, J Kim,'Context-Aware Recommendation Model based on Mobile Application Analysis Platform”. Tools Appl. 2016, 75, 14783-14794.

38. Polatidis N, Georgiadis C.K, Pimenidis,, E.; Stiakakis "Privacy-preserving recommendations in context-aware mobile environments". Infor. Cmput. 2017, 25, 62-79.

39. Zhendong Niu, ChenWei, Xiangyu Zhao, and Yi Li. "A hybrid recommendation algorithm adapted in e-learning," World Wide Web, vol. 17, Springer, 2014.

40. Maizatul Akmar Ismail, Suhendro Khalid Haru,"Context-Aware Recommender System: A Review of Recent Developmental Process and Future Research Direction"2017.

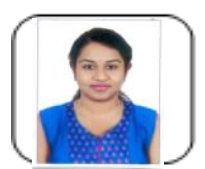

\section{AUTHORS PROFILE}

Shruthi N pursuing $M$. Tech in IS\&E department of RIT. Interested in subjects related to data mining and recommendation technology.

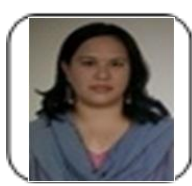

Sunitha R. S. M. Tech degree holder and serving as an assistant professor in IS\&E department of RIT. Interested in subjects related to data mining and software engineering.

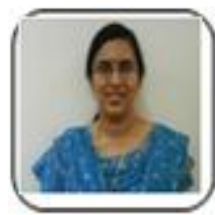

Lincy Mathews $M$. Tech degree holder and serving as an assistant professor in IS\&E department of RIT. Interested in subjects related to machine learning and pattern matching. 